' Department of Restorative Dentistry, Piracicaba Dental School, University of Campinas; Piracicaba, São Paulo, Brazil.

${ }^{2}$ Department of Dentitry, Paulista University, São Paulo, SP, Brazil.

Corresponding author:

Walbert de Andrade Vieira Department of Restorative Dentistry, Endodontics Division State University of Campinas, Piracicaba Dental School Av. Limeira, 901, Areião Endodontics Division CEP. 13414018, Piracicaba, SP Brasil

walbert.vieira18@gmail.com

Editor: Dr Altair A. Del Bel Cury

Received: April 06, 2021

Accepted: July 19, 2021

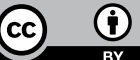

\section{Spectrophotometric analysis of internal bleaching of traumatized teeth with coronal discoloration following regenerative endodontic procedures}

\author{
Jaqueline Lazzari ${ }^{1}$ (D), Walbert Vieira ${ }^{1, *}$ (D), Vanessa \\ Pecorari ${ }^{2}$ (D) Brenda Paula Figueiredo de Almeida \\ Gomes $^{1}$ (D), José Flávio Affonso de Almeida ${ }^{1}$ (D), \\ Adriana de-Jesus-Soares ${ }^{1}$ (D)
}

Aim: The objective of this study was to describe a case series concerning internal bleaching of anterior traumatized teeth that underwent regenerative endodontic procedures (REP). Methods: Seven non-vital maxillary anterior teeth discolored after regenerative endodontic procedures were included and divided into two groups according to the medication protocol used in the REP. (1) Triple antibiotic paste (TAP) group ( $n=4)$; (2) Calcium hydroxide and $2 \%$ chlorhexidine gel $(\mathrm{HC}+\mathrm{CHX})(n=3)$. The bleaching technique used was walking bleach, where sodium perborate associated with distilled water was used. Bleaching agent was replaced weekly until the darkened tooth was slightly lighter than the adjacent tooth. The color was recorded with the aid of a digital spectrophotometer in two moments ( $\mathrm{T} 1$ : prior the first session of bleaching, $\mathrm{T} 2$ : fourteen days after the last session of bleaching). The change in color after the procedure $(\Delta \mathrm{E})$ was calculated and reported in a descriptive analysis. Results: The $\Delta \mathrm{E}$ for all teeth showed color differences exceeding the perceptibility threshold $(\triangle E>3.7)$. Both groups showed similar $\triangle \mathrm{E}$ (TAP. $18.3 \pm 11.5 ; \mathrm{HC}+\mathrm{CHX}$ : $14 \pm 11.2$ ) at the end of the treatment. The average number of sessions needed to achieve satisfactory results was $1.7 \pm 0.6$ for $\mathrm{HC}+\mathrm{CHX}$ group and $2.3 \pm 0.5$ for TAP group. Conclusion: Internal bleaching with sodium perborate associated with distilled water is effective in treating discolored teeth after regenerative endodontic procedures.

Keywords: Tooth bleaching. Regenerative endodontics. Tooth discoloration. 


\section{Introduction}

Traumatic injuries in young patients are the major cause of pulp necrosis in immature permanent teeth ${ }^{1}$. The regenerative endodontic procedure (REP) is a technique based on principles of tissue engineering aimed at providing longitudinal development and strengthening of root walls with use of the inherent capacity of cell proliferation to fill gaps in the body². Ever since the first clinical report of the regenerative endodontic procedure ${ }^{3}$, several protocols have been proposed to promote bacterial decontamination ${ }^{1,4-6}$ and cervical sealing ${ }^{7}$, thus increasing the chances of clinical success.

However, dental crown discoloration is a recurrent after-effect in regenerated teeth $^{7-9}$. The main cause of this discoloration has been attributed to the use of the triple antibiotic pastes (TAP) used as intra-canal medication ${ }^{8,10,11}$. A clinical trial by Nagata et al. ${ }^{8}$ (2014) observed that $83 \%$ of the teeth subjected to this medication protocol had some degree of coronary discoloration. Although this intracanal medication has a great antibacterial spectrum, it is hypothesized that the minocycline (a component of TAP) is the responsible for this discoloration, since this substance has the property of binding calcium ions, forming an insoluble complex, which when incorporated into the dentin matrix, leads to darkening².

Another factor related to coronary discoloration following REP is the use of calcium silicate-based cervical barriers ${ }^{1,7,9,10,12-15}$ and their interaction with the blood clot $^{16}$, especially those that have bismuth oxide in their composition, which when in contact with collagen matrix result in a darkened precipitate ${ }^{13}$.

Internal bleaching is a consolidated option for the resolution of cases of coronary discoloration in non-vital teeth, even in cases related to traumatic injuries ${ }^{17,18}$. Recent in vitro studies have shown satisfactory results regarding the efficacy of internal bleaching in darkened teeth after the use of triple antibiotic paste or after the use of calcium silicate-based cervical barriers ${ }^{10,19}$. However, few in vivo studies regarding internal bleaching of teeth treated by regenerative endodontic procedures have been found in the literature ${ }^{20-23}$, mostly case reports.

Thus, the aim of this study was to describe a series of cases concerning internal teeth whitening in traumatized teeth that underwent regenerative endodontic procedures. We tested the null hypothesis that the internal bleaching with sodium perborate will not be effective in treating darkened teeth after regenerative endodontic procedures.

\section{Materials and Methods}

\section{Protocol and Ethical Criteria}

All national (CNS/MS Resolution No. 466/2012) and international (Helsinki Declaration) precepts related to research ethics involving human beings were respected. The project was approved by an Independent Human Research Ethics Committee (Protocol number: 092/2015). All patients and respective guardians signed a consent form. 


\section{Study design and participants selection}

This is a case series study in which maxillary anterior teeth discolored after regenerative endodontic procedures were selected during the follow up of a previous study $^{8}$ at the Dental Trauma Service of the School of Dentistry of Piracicaba, Brazil. All teeth submitted to REP in the previous study ${ }^{8}$ were diagnosed with pulp necrosis based on clinical (negative response to thermal and electric tests / presence of sinus tract or tenderness to percussion) and radiographic aspects (presence of periapical radiolucency).

The following inclusion criteria were defined: 1) Success of the regenerative endodontic procedure. Success was defined as the tooth remaining present in the arch and absence of clinical symptoms (tenderness to palpation or percussion, sinus tract and spontaneous pain); 2) Absence of periapical lesion; 3) Absence of gingival inflammation; 4) Absence of external cervical root resorption; 5) Full or minimally restored crown; 6) Absence of orthodontic appliance.

Patients who had discolored teeth but did not return to start treatment or refused to participate were excluded from the sample.

\section{Division of groups}

Dental elements were divided into two groups, according to the medication protocol used in regenerative endodontic procedures:

- TAP Group: Group with teeth discolored after regenerative endodontic procedure, treated with triple antibiotic paste (ciprofloxacin $250 \mathrm{mg}$, metronidazole $400 \mathrm{mg}$ and minocycline $50 \mathrm{mg}, 1: 1: 1$ ) and sealed with white MTA (Angelus ${ }^{\mathrm{TM}}$, Londrina, Brazil), coltosol (Coltene-Whaledent, Langenau, Germany) and composite resin (Z250 Filtek; 3M ESPE, Sumaré, São Paulo, Brazil).

- $\quad \mathrm{HC}+\mathrm{CHX}$ group: Group with teeth discolored after regenerative endodontic procedure, treated with calcium hydroxide (Biodynamics, Ibiporã, PR, Brazil) and 2\% chlorhexidine gel (Endogel, Itapetininga, São Paulo, Brazil), at a 1:1 ratio. Access cavities were sealed with white MTA (Angelus ${ }^{\mathrm{TM}}$, Londrina, Brazil), coltosol (Coltene-Whaledent, Langenau, Germany) and composite resin (Z250 Filtek; 3M ESPE, Sumaré, São Paulo, Brazil).

\section{Clinical protocol of internal tooth bleaching}

The bleaching technique used was walking bleach, where sodium perborate associated with distilled water was used. At initial consultation, a digital periapical radiographic scan (Apixia PSP Scanner, CA, USA) was performed in the region of the tooth to be bleached, followed by dental prophylaxis.

The color assessment was performed with the VITA Easyshade digital spectrophotometer (Vita Easyshade, Vita Zahnfabrik). Photographic records were also performed at the beginning and end of bleaching (Nikon ${ }^{\mathrm{TM}}$ D3200, Minato, Tokyo, Japan).

Clinical crown height was recorded with a millimeter-calibrated instrument and a rubber stop. Rubber-dam isolation and removal of all restorative material was subsequently performed with a high-speed spherical diamond tip pulp chamber 
(KG Sorensen, Barueri, SP, Brazil) under refrigeration (Figure 1A). The MTA, used as cervical barrier, was removed $2 \mathrm{~mm}$ below the gingival margin and a new coltosol cervical sealing (Coltene AG, Altstatten, Switzerland) was performed (Figure 1B).

The bleaching agent was manipulated in a 2:1 ratio using two measurements of the bleaching agent (sodium perborate) for a vehicle portion (distilled water) [24,25] (Figure 1C). A polymerized cotton ball moistened with dentin adhesive was inserted and the cavity was provisionally sealed with composite resin (Figure 1D). Occlusal adjustment was performed every restoration change.

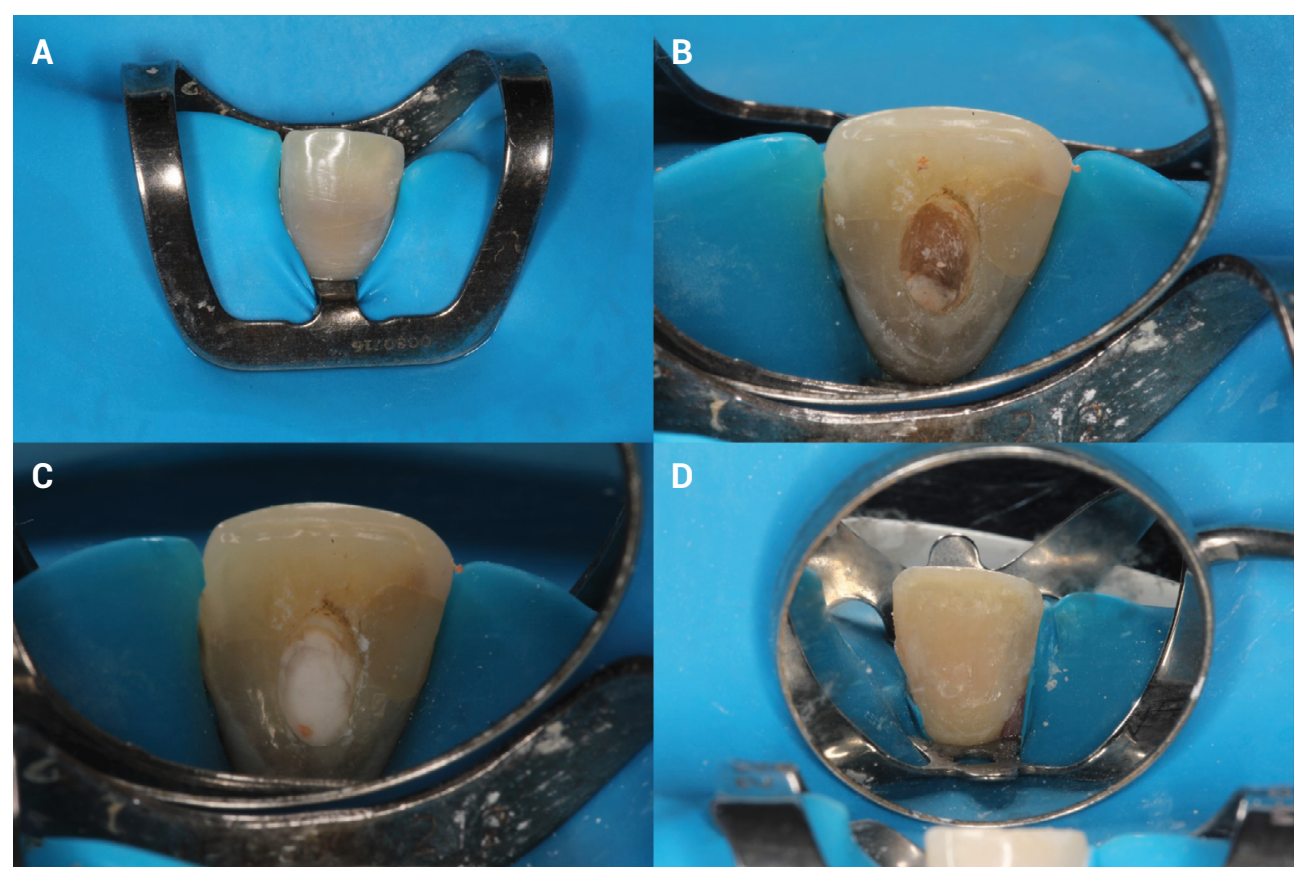

Figure 1. Clinical protocol of internal bleaching. (A) Rubber-dam isolation and removal of all restorative material; (B) Removal of the MTA and insertion of $2 \mathrm{~mm}$ of Coltosol as a cervical barrier; (C) Insertion of the bleaching agent; (D) Temporary restoration with composite resin.

The bleaching agent changes were performed every seven days until the discolored tooth was slightly lighter than the adjacent tooth, with a limit of five sessions of internal tooth bleaching. After the bleaching sessions, the pulp chamber was washed with water spray and a calcium hydroxide paste (Biodynamics, Ibiporã, PR, Brazil) as well as distilled water were applied. After 14 days, sealing was removed, and permanent restoration was performed with composite resin.

\section{Color assessment method}

The color was recorded in two moments: (T1) The baseline was assessed prior the first session of bleaching (in the moment that the discoloration was diagnosed during the follow up visits after the REP); (T2) the second assessment was done fourteen 
days after the last session of bleaching. The color was recorded in triplicate with the aid of the previously calibrated Vita Easyshade Advance 4.0 digital spectrophotometer (Vita Zahnfabrik, Bad Sackingen, Germany). A condensation silicone tray was fabricated (Clonage, Nova DFL, RJ, Brazil) with an opening in the cervical region belonging to the buccal surface of the darkened tooth in order to eliminate the influence of external illumination and standardize readings.

The color of each dental element was assessed using the CIELAB system (Commission Internationale de L'Eclairage, Vienna, Austria). $L * a *$ and $b *$ values were recorded: $L *$ refers to lightness, from 0 (black) to 100 (white); $a *$ values determine the amount of red (positive values) or green (negative values); $b$ * values refer to the measurement of yellow (positive values) or blue (negative values). Comparison between the values obtained from $L * a *$ and $b *$ are expressed as $\Delta E$, which describes the color difference between the initial and final values of tooth bleaching ${ }^{10}$. The value of $\Delta E$ was obtained by the following formula:

$$
\Delta E=\left[\left(L_{1}-L_{0}\right)^{2}+\left(a_{1}-a_{0}\right)^{2}+\left(b_{1}-b_{0}\right)^{2}\right]^{1 / 2}
$$

Perceptible differences in the human eye were considered, and clinically relevant, $\Delta E$ values above $3.7^{24}$.

\section{Data analysis}

Descriptive analysis of groups with data on age, darkening time, and number of sessions. $\triangle E$ were calculated and reported as mean, standard deviation and median.

\section{Results}

Of the 23 upper incisors subjected to regenerative endodontic procedures in the study by Nagata et al. ${ }^{8}$, thirteen presented coronal discoloration during follow-up, of which only seven teeth were included in the sample (Figure 2). The average age of participants was $12.7( \pm 4.1)$ years. The time from REP to internal bleaching procedure varied from 1 to 4 years (Table 1).

All teeth included in the study were maxillary incisors, with the central incisors representing $73 \%$ of the sample, whereas lateral incisors represented $27 \%$. The frequency and distribution of teeth according to the type of medication are presented in Table1. 


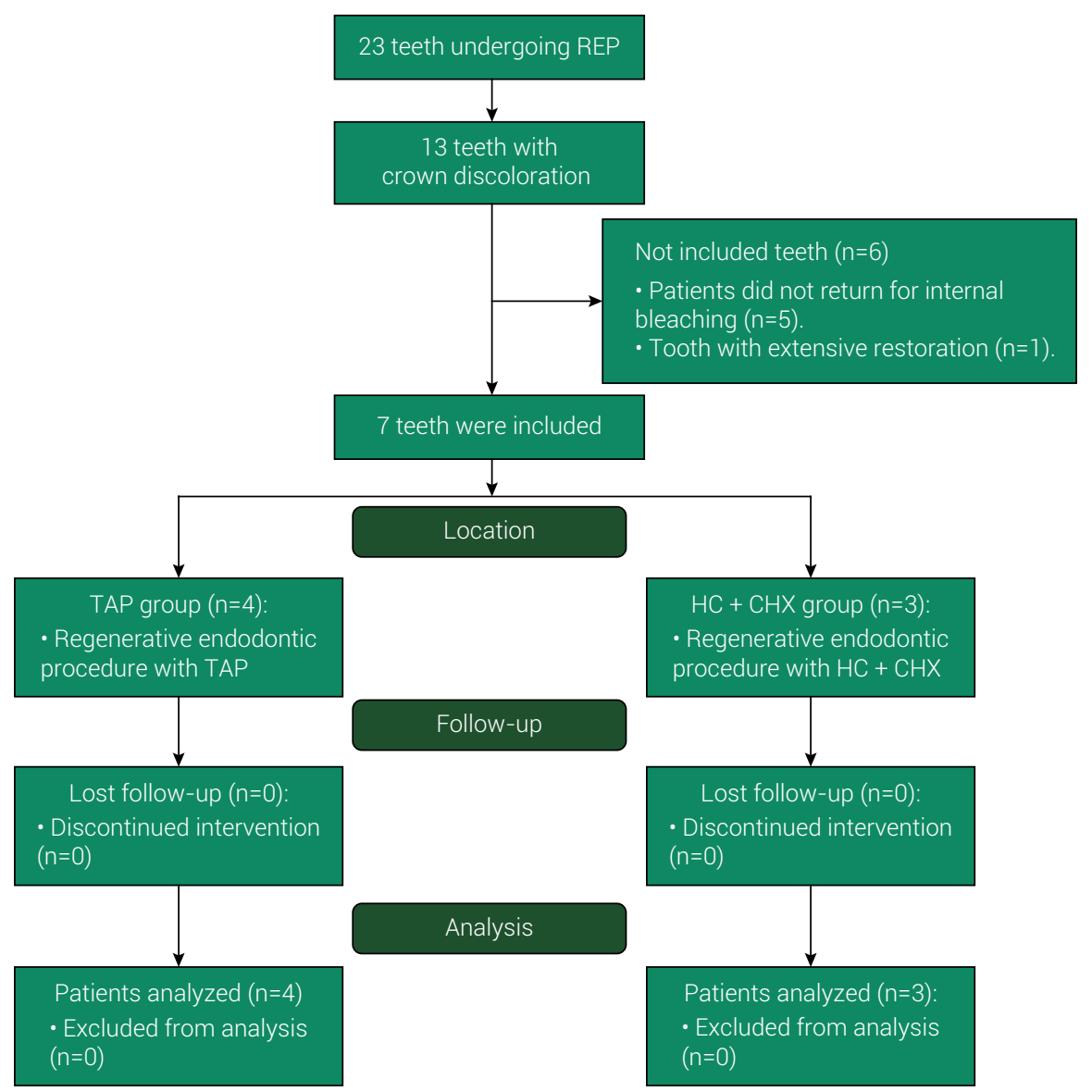

Figure 2. Flowchart of the distribution of the teeth included in the study.

Table 1. Main characteristics of the cases.

\begin{tabular}{lcccccc}
\hline Pacient & Tooth & $\begin{array}{c}\text { Type } \\
\text { of TDI }\end{array}$ & Age (years) & $\begin{array}{c}\text { Darkening } \\
\text { time' (years) }\end{array}$ & $\Delta \mathrm{E}$ & $\begin{array}{c}\text { Number of } \\
\text { sessions }\end{array}$ \\
\hline Group HC $+\mathrm{CHX}$ & 11 & Lateral luxation & 14 & 4 & 12.2 & 2 \\
\hline 1 & 12 & Lateral luxation & 8 & 1 & 3.8 & 1 \\
\hline 2 & 11 & Extrusion & 20 & 1 & 26.0 & 2 \\
\hline 3 & & & $14 \pm 6.0$ & $2 \pm 1.7$ & $14 \pm 11.2$ & $1.7 \pm 0.6$ \\
\hline Mean \pm SD & & 14.0 & 1.0 & 12.2 & 2.0 \\
\hline Median & & Lateral luxation & 13 & 4 & 33.5 & 2 \\
\hline Group TAP & 22 & Lateral luxation & 14 & 4 & 14.1 & 2 \\
\hline 4 & Extrusion & 12 & 2 & 19.4 & 3 \\
\hline 1 & 21 & Lateral luxation & 8 & 1 & 6.2 & 2 \\
\hline 5 & 11 & & $11.8 \pm 2.6$ & $2.8 \pm 1.5$ & $18.3 \pm 11.5$ & $2.3 \pm 0.5$ \\
\hline 2 & & & 12.5 & 3 & 16.8 & 2.0 \\
\hline Mean $\pm S D$ & & & & & & \\
\hline Median & & & & & & \\
\hline
\end{tabular}

TDI - Traumatic dental injuries; ${ }^{1}$ Darkening time since the regenerative endodontic procedure. 


\section{Change in color analysis}

In both groups, the color difference between the initial and final values of tooth bleaching were greater than the minimum value $(\triangle E>3.7)$ in all teeth, with values ranging from 3.8 to 33.5. Figure 3 shows before and after internal bleaching of all cases included in the study.

The number of sessions required to achieve satisfactory results was similar between groups, ranging from one to three sessions (Table 1).
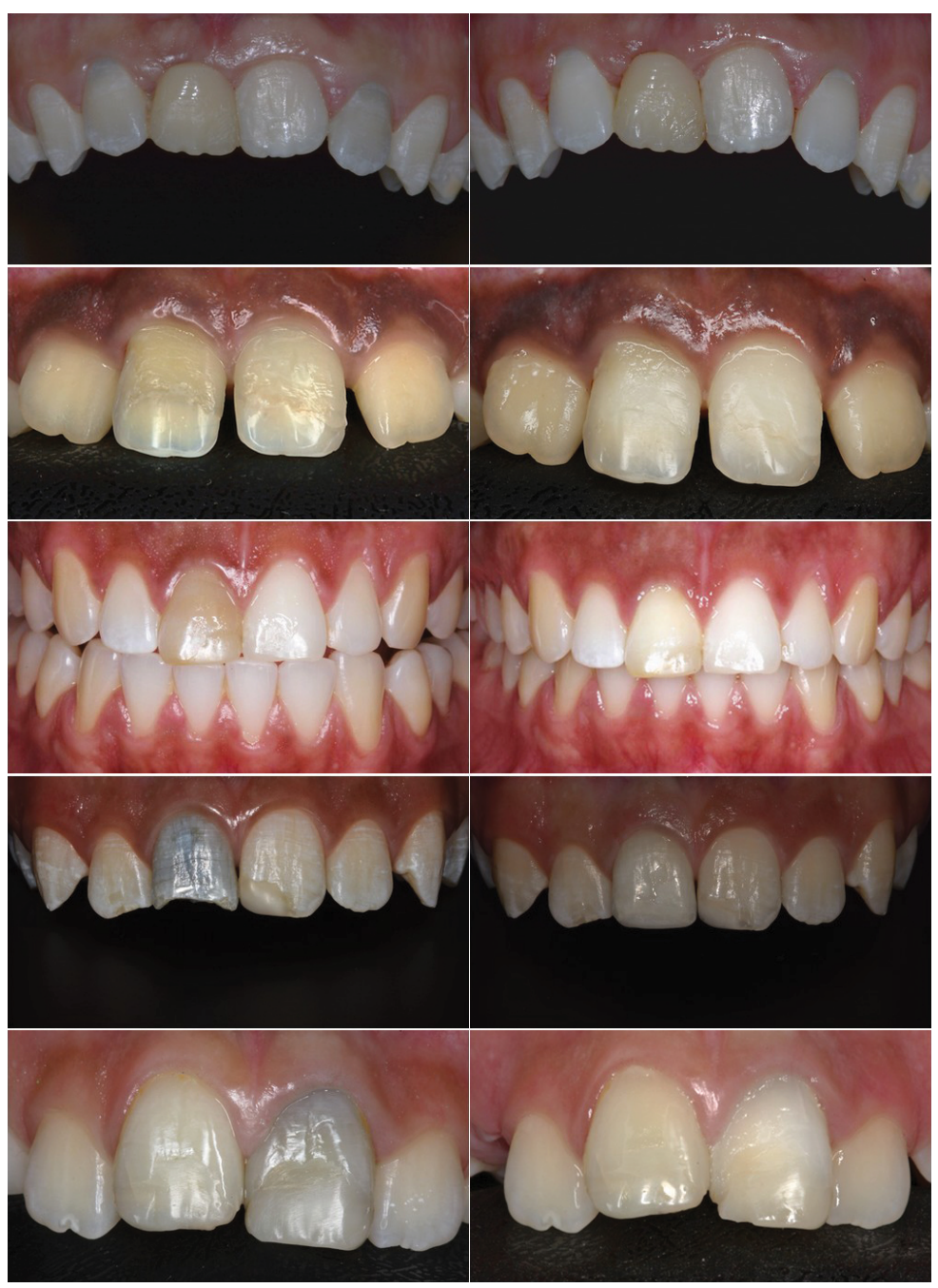

Figure 3. Clinical appearance of the cases included in the study. $(A, C, E, G, I)$ Clinical appearance before internal bleaching, where it is possible to observe the crown discoloration of the incisors submitted to the regenerative endodontic procedure; $(\mathrm{B}, \mathrm{D}, \mathrm{F}, \mathrm{H}, \mathrm{J})$ Clinical appearance 14 days after the last internal bleaching session. 


\section{Discussion}

This study described a series of cases in which non-vital traumatized permanent teeth treated by different medication protocols during the regenerative endodontic procedure underwent internal tooth bleaching procedure. Internal dental bleaching with sodium perborate showed to be an effective treatment modality for discolored teeth following pulp regenerative endodontic procedures. Thus, the null hypothesis was rejected.

The REP is an effective therapy for the treatment of necrotic immature teeth, which combines decontamination techniques to eliminate microorganisms from the interior of the root canal and tissue stimulation techniques that will promote the continuation of root development ${ }^{25}$. Despite its clinical success ${ }^{1,8}$, the bond strength of restorative materials is influenced by the biomaterials used as a cervical barrier ${ }^{26-27}$, which can compromise the post-treatment sealing; in addition, some teeth show crown discoloration during the follow-up, often caused by intracanal medications and materials used in the procedure $\mathrm{p}^{7-12,19}$.

The most used substances in the internal tooth bleaching technique are hydrogen peroxide and sodium perborate ${ }^{28}$. The use of sodium perborate associated with distilled water is indicated to reduce the risk of external root resorption, as this combination is less toxic to periodontal ligament cells ${ }^{29}$. In addition, there are no reports of external root resorption related to its use ${ }^{18}$. For this reason, we chose to use sodium perborate associated with distilled water, considering the biological aspects and the risk of damage to periodontal tissues, especially in immature teeth with large dentinal tubules and a history of trauma.

The efficacy of internal bleaching already been proven in several in vitro and in vivo studies that included factors related to REP as etiologies of tooth discoloration, such as the use of MTA as a cervical barrier ${ }^{30-31}$, the use of triple antibiotic pastes ${ }^{10,19}$, or the presence of the blood clot $^{16}$.

The most described MTA-related darkening mechanisms are heavy metal ion release and interaction of bismuth oxide with the collagen matrix, which will result in a darkened precipitate ${ }^{30}$; interaction with the stimulated blood clot during the regenerative endodontic procedure ${ }^{31}$. However, studies have shown that internal bleaching is effective in reversing darkening caused by $\mathrm{MTA}^{10,31}$, as was observed in our study, where all cases showed clinically relevant change in color noticeable to the human eye $(\triangle E>3.7)$. Previous study observed that most of the discoloration in these cases are within the MTA and not in the dentin, so the removal of part of the MTA could improve the crown color in association with the internal bleaching ${ }^{32}$.

Another cause related to dental discoloration after REP is the use of triple antibiotic pastes $^{8-11}$. In our study, of the thirteen discolored teeth present in the initial sample, nine had been treated with triple antibiotic paste (TAP), whereas only four teeth treated with calcium hydroxide and chlorhexidine had darkened. The main reason for this finding is attributed to the presence of minocycline in the constitution of TAP. The most accepted hypotheses that explain these findings are the possible interaction of minocycline with collagen, resulting in pigmented bioproducts, and the binding of minocycline to the calcium ion of dentin by chelation 6 . Thus, the use of calcium 
hydroxide associated with chlorhexidine $2 \%$ gel reduces the chances of coronary darkening after regenerative endodontic procedures ${ }^{1}$ and may be an alternative to the use of TAP paste ${ }^{4,8}$.

As for the results of internal bleaching, regardless of the intracanal medication utilized, all teeth showed significant $\Delta \mathrm{E}$ changes, validating the results of in vitro and in vivo studies and other case reports that showed satisfactory results for internal

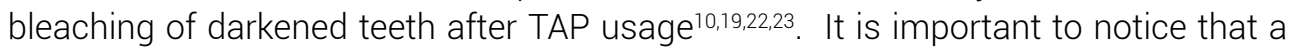
recent evidence showed that although the internal bleaching of discolored tooth by TAP cause higher color changes in the dentin, the enamel plays an important role in the final color perception ${ }^{19}$. In this context, during the REP we need to pay attention in the materials used and its impact on both enamel and dentin and establish protocols to avoid tooth discoloration ${ }^{33}$.

The use of blood clots as scaffold during regenerative endodontic therapy has also been associated to coronary darkening ${ }^{31}$. In all teeth used in this study, blood clots were used as scaffold during REP. There is no consensus in the literature able to explain the darkening mechanism of the tooth discoloration caused by blood clot; however, the most accepted hypotheses are the accumulation of hemoglobin and hematin molecules ${ }^{31,33}$ or their interaction with materials based on calcium silicate, which would result in the darkening of the material ${ }^{16}$. We believe that in the cases of this study, a combination of both factors may influence coronary darkening, since MTA barriers are positioned close to the cervical third of the teeth and in direct contact with the blood clot. However, further studies should be conducted to verify the relationship of coronary discoloration with the presence of blood clots, as well as the efficacy of bleaching agents in such situations.

This study has certain limitations. The first concerns the small number of patients involved in each group. In addition, study design represents an important limitation since case series studies have low scientific evidence. Randomized clinical trials are encouraged to reinforce the findings. However, this is an original study, being the largest case series of traumatized teeth undergoing regenerative endodontic procedures and internal bleaching.

In conclusion, internal teeth bleaching with sodium perborate is effective in treating coronal discoloration after regenerative endodontic procedures.

\section{Acknowledgements}

This study was financed in part by CAPES - Finance Code 001. The authors thank Espaço da Escrita - Pro-Reitoria de Pesquisa - UNICAMP - for the language services provided.

\section{Data availability}

Datasets related to this article will be available upon request to the corresponding author.

\section{Conflicts of interest}

None. 


\section{References}

1. Pereira AC, Oliveira ML, Cerqueira-Neto ACCL, Gomes BPFA, Ferraz CCR, Almeida JFA, et al. Treatment outcomes of pulp revascularization in traumatized immature teeth using calcium hydroxide and 2\% chlorhexidine gel as intracanal medication. J Appl Oral Sci. 2020 Sep 25;28:e20200217. doi: 10.1590/1678-7757-2020-0217.

2. Kim SG, Malek M, Sigurdsson A, Lin LM, Kahler B. Regenerative endodontics: a comprehensive review. Int Endod J. 2018 Dec;51(12):1367-88. doi: 10.1111/iej.12954.

3. Banchs F, Trope M. Revascularization of immature permanent teeth with apical periodontitis: new treatment protocol? J Endod. 2004 Apr;30(4):196-200. doi: 10.1097/00004770-200404000-00003.

4. Nagata JY, Soares AJ, Souza-Filho FJ, Zaia AA, Ferraz CC, Almeida JF, et al. Microbial evaluation of traumatized teeth treated with triple antibiotic paste or calcium hydroxide with $2 \%$ chlorhexidine gel in pulp revascularization. J Endod. 2014 Jun;40(6):778-83. doi: 10.1016/j.joen.2014.01.038.

5. Albuquerque MT, Evans JD, Gregory RL, Valera MC, Bottino MC. Antibacterial TAP-mimic electrospun polymer scaffold: effects on P. gingivalis-infected dentin biofilm. Clin Oral Investig. 2016 Mar;20(2):387-93. doi: 10.1007/s00784-015-1577-2.

6. Mohammadi Z, Jafarzadeh H, Shalavi S, Yaripour S, Sharifi F, Kinoshita JI. A review on triple antibiotic paste as a suitable material used in regenerative endodontics. Iran Endod J. 2018;13(1):1-6. doi: 10.22037/iej.v13i1.17941.

7. Aly MM, Taha SEE, El Sayed MA, Youssef R, Omar HM. Clinical and radiographic evaluation of Biodentine and Mineral Trioxide Aggregate in revascularization of non-vital immature permanent anterior teeth (randomized clinical study). Int J Paediatr Dent. 2019 Jul;29(4):464-73. doi: 10.1111/ipd.12474.

8. Nagata JY, Gomes BP, Rocha Lima TF, Murakami LS, de Faria DE, Campos GR, et al. Traumatized immature teeth treated with 2 protocols of pulp revascularization. J Endod. 2014 May;40(5):606-12. doi: 10.1016/j.joen.2014.01.032.

9. Santos LGPD, Chisini LA, Springmann CG, Souza BDM, Pappen FG, Demarco FF, et al. Alternative to avoid tooth discoloration after regenerative endodontic procedure: a systematic review. Braz Dent J. 2018 Sep-Oct;29(5):409-18. doi: 10.1590/0103-6440201802132.

10. Oliveira LSJ, Silva PFD, Figueiredo FED, Brito-Junior M, Sousa-Neto MD, Faria-E-Silva AL. In vitro evaluation of tooth discoloration induced by regenerative endodontic therapy and the effectiveness of the walking bleach technique. Int J Esthet Dent. 2019;14(3):300-9.

11. Fundaoğlu Küçükekenci F, Çakici F, Küçükekenci AS. Spectrophotometric analysis of discoloration and internal bleaching after use of different antibiotic pastes. Clin Oral Investig. 2019 Jan;23(1):161-7. doi: 10.1007/s00784-018-2422-1.

12. Tripathi $\mathrm{R}$, Cohen $\mathrm{S}, \mathrm{Khanduri} \mathrm{N}$. Coronal tooth discoloration after the use of white mineral trioxide aggregate. Clin Cosmet Investig Dent. 2020 Sep 30;12:409-14. doi: 10.2147/CCIDE.S266049.

13. Marciano MA, Costa RM, Camilleri J, Mondelli RF, Guimarães BM, Duarte MA. Assessment of color stability of white mineral trioxide aggregate angelus and bismuth oxide in contact with tooth structure. J Endod. 2014 Aug;40(8):1235-40. doi: 10.1016/j.joen.2014.01.044.

14. Marques Junior RB, Baroudi K, Santos AFCD, Pontes D, Amaral M. Tooth discoloration using calcium silicate-based cements for simulated revascularization in vitro. Braz Dent J. 2021;32(1):53-8. doi: 10.1590/0103-6440202103700.

15. Yoldaş SE, Bani M, Atabek D, Bodur H. Comparison of the potential discoloration effect of bioaggregate, biodentine, and white mineral trioxide aggregate on bovine teeth: in vitro research. J Endod. 2016 Dec;42(12):1815-8. doi: 10.1016/j.joen.2016.08.020. 
16. Guimarães BM, Tartari T, Marciano MA, Vivan RR, Mondeli RF, Camilleri J, et al. Color stability, radiopacity, and chemical characteristics of white mineral trioxide aggregate associated with 2 different vehicles in contact with blood. J Endod. 2015 Jun;41(6):947-52. doi: 10.1016/j.joen.2015.02.008.

17. Plotino G, Buono L, Grande NM, Pameijer CH, Somma F. Nonvital tooth bleaching: a review of the literature and clinical procedures. J Endod. 2008 Apr;34(4):394-407. doi: 10.1016/j.joen.2007.12.020.

18. Abbott P, Heah SY. Internal bleaching of teeth: an analysis of 255 teeth. Aust Dent J. 2009 Dec;54(4):326-33. doi: 10.1111/j.1834-7819.2009.01158.x.

19. Santana TR, BraganÇa RMF, Correia ACC, Oliveira IM, Faria-E-Silva AL. Role of enamel and dentin on color changes after internal bleaching associated or not with external bleaching. J Appl Oral Sci. 2020 Dec;29:e20200511. doi: 10.1590/1678-7757-2020-0511.

20. Fagogeni I, Falgowski T, Metlerska J, Lipski M, Górski M, Nowicka A. Efficiency of teeth bleaching after regenerative endodontic treatment: a systematic review. J Clin Med. 2021 Jan;10(2):316. doi: 10.3390/jcm10020316.

21. Timmerman A, Parashos P. Bleaching of a discolored tooth with retrieval of remnants after successful regenerative endodontics. J Endod. 2018 Jan;44(1):93-7. doi: 10.1016/j.joen.2017.08.032

22. Kirchhoff AL, Raldi DP, Salles AC, Cunha RS, Mello I. Tooth discolouration and internal bleaching after the use of triple antibiotic paste. Int Endod J. 2015 Dec;48(12):1181-7. doi: 10.1111/iej.12423.

23. Antov H, Duggal MS, Nazzal H. Management of discolouration following revitalization endodontic procedures: a case series. Int Endod J. 2019 Nov;52(11):1660-70. doi: 10.1111/iej.13160.

24. Johnston WM, Kao EC. Assessment of appearance match by visual observation and clinical colorimetry. J Dent Res. 1989 May;68(5):819-22. doi: 10.1177/00220345890680051301.

25. American Association of Endodontists. AAE Clinical considerations for a regenerative procedure. 2018 Jan 4 [cited 2021 May 25]. Available from: https://f3f142zs0k2w1kg84k5p9i1 o-wpengine.netdna-ssl. com/specialty/wp-content/uploads/sites/2/2018/06/ConsiderationsForRegEndo_AsOfApril2018.pdf.

26. Hursh KA, Kirkpatrick TC, Cardon JW, Brewster JA, Black SW, Himel VT, et al. Shear bond comparison between 4 bioceramic materials and dual-cure composite resin. J Endod. 2019 Nov;45(11):1378-83. doi: 10.1016/j.joen.2019.07.008.

27. Pereira AC, Pallone MV, Marciano MA, Cortellazzi KL, Frozoni M, Gomes BP, et al. Effect of intracanal medications on the interfacial properties of reparative cements. Restor Dent Endod. 2019 May;44(2):e21. doi: 10.5395/rde.2019.44.e21.

28. de Oliveira DP, Teixeira EC, Ferraz CC, Teixeira FB. Effect of intracoronal bleaching agents on dentin microhardness. J Endod. 2007 Apr;33(4):460-2. doi: 10.1016/j.joen.2006.08.008.

29. Kinomoto Y, Carnes DL Jr, Ebisu S. Cytotoxicity of intracanal bleaching agents on periodontal ligament cells in vitro. J Endod. 2001 Sep;27(9):574-7. doi: 10.1097/00004770-200109000-00005.

30. Santos LG, Felippe WT, Souza BD, Konrath AC, Cordeiro MM, Felippe MC. Crown discoloration promoted by materials used in regenerative endodontic procedures and effect of dental bleaching: spectrophotometric analysis. J Appl Oral Sci. 2017;25(2):234-42. doi: 10.1590/1678-77572016-0398.

31. Shokouhinejad N, Razmi H, Farbod M, Alikhasi M, Camilleri J. Coronal tooth discoloration induced by regenerative endodontic treatment using different scaffolds and intracanal coronal barriers: a 6-month ex vivo study. Restor Dent Endod. 2019 Jul;44(3):e25. doi: 10.5395/rde.2019.44.e25.

32. Belobrov I, Parashos P. Treatment of tooth discoloration after the use of white mineral trioxide aggregate. J Endod. 2011 Jul;37(7):1017-20. doi: 10.1016/j.joen.2011.04.003.

33. Shokouhinejad N, Khoshkhounejad M, Alikhasi M, Bagheri P, Camilleri J. Prevention of coronal discoloration induced by regenerative endodontic treatment in an ex vivo model. Clin Oral Investig. 2018 May;22(4):1725-31. doi: 10.1007/s00784-017-2266-0. 